\title{
ENSINO SUPLEMENTAR NO CONTEXTO BRASILEIRO: UMA ANÁLISE BASEADA NOS DADOS DO ENEM
}

\author{
Fernando Vizotto Galvão ${ }^{1}$
}

\begin{abstract}
RESUMO: Dialogando com a literatura que trata de shadow education, assim como com elementos da abordagem bourdieusiana, os quais tratam das relações entre o espaço social e as práticas dos indivíduos, este artigo procura explorar, a partir dos dados do Exame Nacional do Ensino Médio (ENEM) de 2008, a existência ou não de padrões de participação em cursos suplementares. Submetidos à Análise de Correspondências Múltiplas, os dados revelaram homologias e distinções relativas à participação em diferentes cursos suplementares, assim como certa relação entre os padrões de participação em determinados cursos e a condição social dos estudantes.
\end{abstract}

Palavras-chave: Ensino suplementar. Shadow education. Desigualdades educacionais.

\section{SUPPLEMENTARY EDUCATION IN BRAZILIAN CONTEXT: AN ANALYSIS BASED ON ENEM DATA}

\begin{abstract}
Dialoguing with the literature on shadow education, as well as with elements of the bourdieusian approach dealing with the relationship between social space and individual practices, this article aimed at analyzing the existence or not of participation patterns in supplementary courses using data from the High School National Exam (ENEM; from Portuguese, Exame Nacional do Ensino Médio) 2008. Submitted to a Multiple Correspondence Analysis, the data revealed homologies and distinctions regarding participation in different supplementary courses, as well as a relation between the patterns of participation in certain courses and the students` social condition.
\end{abstract}

Keywords: Supplementary education. Shadow education. Educational inequalities.

\section{ENSEÑANZA SUPLEMENTARIA EN EL CONTEXTO BRASILEÑO: UN ANÁLISIS BASEADO EM DATOS DE ENEM}

RESUMEN: Dialogando con la literatura que trata de shadow education, así como con elementos del enfoque bourdieusiano que tratan de las relaciones entre el

*Este artigo resulta de pesquisa de doutorado em andamento, intitulada Vantagens Denegadas, Trajetórias (im)Possíveis: Uma análise das práticas de shadow education no Brasil e desenvolvida sob a orientação do Professor doutor Romualdo Luiz Portela de Oliveira, na Faculdade de Educação da Universidade de São Paulo.

1.Universidade de São Paulo - Faculdade de Educação - São Paulo (SP), Brasil. E-mail: fernando.galvao@usp.br 
espacio social y las prácticas de los individuos, se buscó analizar, en los datos del Exame Nacional de Enseñanza Secundaria (ENEM; de portugués, Exame Nacional do Ensino Médio) de 2008, la existencia o no de patrones de participación en cursos suplementarios. Sometidos a el Análisis de Correspondencias Múltiples, los datos revelaron homologaciones y distinciones relativas a la participación en diferentes cursos suplementarios, así como una cierta relación entre los patrones de participación en determinados cursos y la condición social de los estudiantes.

Palabras-clave: Enseñanza suplementaria. Shadow education. Desigualdades educativas.

\section{Introdução}

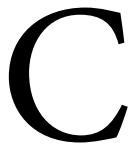

itada por Bourdieu (2013, p. 45-46) como uma das formas mais óbvias da ação do privilégio cultural, a prática de recorrer a atividades suplementares (geralmente aulas ou cursos oferecidos fora do tempo dedicado ao ensino regular), ainda que antiga (HUSSEIN, 1987), apenas recentemente tem sido objeto de investigação sistemática.

Os estudos dedicados à análise desse tipo de experiência educativa, que se multiplicaram a partir da década de 1990, costumam utilizar os termos shadow education ou private tuition, na literatura em língua inglesa, ou mercado das explicações, nas pesquisas conduzidas por autores portugueses, para delimitar um conjunto de atividades que, em uma aproximação com o contexto brasileiro, talvez possam ser entendidas como práticas de ensino suplementar. Bray justifica o uso do termo shadow education:

A metáfora de uma sombra é apropriada em muitos sentidos. Primeiro, o ensino suplementar privado só existe porque o ensino regular existe; segundo, conforme mudam tamanho e forma do ensino regular, tamanho e forma do ensino suplementar também mudam; terceiro, em quase todas as sociedades, muito mais atenção é dada ao ensino regular do que à sua sombra; $\mathrm{e}$ quarto, as características do sistema de shadow education são muito menos nítidas que aquelas do sistema de ensino regular (2007, p. 17, tradução nossa).

Em linhas gerais, pode-se entender que o termo designa um conjunto de atividades educacionais ofertadas no mercado, à parte do ensino regular, pelo qual parte das famílias está disposta a pagar (e, antes de estar disposta, tem condições de pagar) e que se soma às experiências educativas experimentadas por crianças e jovens nas escolas e em suas casas, entre outros espaços possíveis.

Ainda em relação ao escopo das pesquisas sobre o tema, destaca-se que a maior parte dos estudos opta por considerar shadow education as atividades suplementares que guardam alguma correspondência com as disciplinas ou conteúdos do ensino regular. Nesse caso, são exemplos recorrentes desse tipo de atividade aulas de reforço escolar, cursos preparatórios para os exames que medeiam o ingresso no Ensino Superior e cursos de idiomas (BRAY, 2007; BRAY; KWOK, 2003; COSTA et al., 2013; BUCHMANN et al., 2010). Alguns estudos, contudo, optam por uma classificação menos restritiva do que pode ser considerado shadow education, incluindo, por exemplo, atividades esportivas e artísticas em suas análises (LIU; BRAY, 2017; KIRBY, 2016).

Além do exposto, pode-se dizer que os estudos sobre shadow education costumam limitar suas análises à participação, em atividades de ensino suplementar, de crianças e jovens que ainda se encontrem 
na educação básica ou sejam recém-egressos do Ensino Médio, já que, nesse último caso, é relativamente comum a participação dos estudantes em cursos preparatórios para os processos seletivos associados ao ingresso no Ensino Superior.

Dadas a proliferação dessas atividades nas últimas décadas (BRAY, 2007; SILOVA, 2010; COSTA et al., 2013), as consequências que elas podem ter em relação a desigualdades educacionais (tendo em vista que só frequentam essas atividades os estudantes que detêm condições materiais e simbólicas de acessá-las) e a existência de poucos trabalhos que tratem do tema no contexto brasileiro, este artigo se propõe explorar a participação de estudantes brasileiros em algumas atividades de ensino suplementar a partir dos dados do Exame Nacional do Ensino Médio (ENEM) de 2008, procurando observar se a participação nos cursos considerados guarda alguma relação com a condição social dos indivíduos e se há alguma tendência de a participação em determinado curso estar associada à participação em outros tipos de curso.

\section{Alguns Apontamentos da Pesquisa Internacional sobre Shadow Education}

Talvez uma das maiores dificuldades envolvidas no estudo da participação de estudantes em atividades de ensino suplementar seja dar conta da variedade de possibilidades de tipos e formatos de cursos existentes em cada contexto. A dificuldade de lidar com essa diversidade de possibilidades de experiências educativas tem sido enfrentada, em parte, pelos pesquisadores dedicados ao estudo do tema. Mark Bray, um dos autores que se destacam nesse tipo de esforço, geralmente caracteriza as atividades de shadow education a partir da ótica da oferta e da demanda, segundo as formas de participação e as disciplinas mais procuradas, de acordo com a intensidade da frequência semanal ou mensal a essas atividades e de acordo com a escala da participação em cada contexto (BRAY; 2007; 2011). Além disso, é comum que as atividades de ensino suplementar sejam classificadas segundo o motivo que leva os estudantes ou suas famílias a demandá-las. Nesse caso, cursos suplementares costumam ser divididos entre aqueles dedicados a sanar ou prevenir dificuldades dos alunos no ensino regular e aqueles direcionados a viabilizar um preparo adicional ao experimentado no ensino regular (SOUTHGATE, 2009; BRAY, 2007; BAKER et al., 2001).

Em relação às formas de participação, são apontadas como possibilidades aulas ou cursos oferecidos presencialmente ou a distância; em grupo ou individualmente; em instituições que contam com salas de aula ou na residência dos alunos ou dos profissionais que oferecem as aulas ou cursos. Em geral, as formas de participação variam segundo o tipo de atividade (p. ex., cursos preparatórios para o ingresso no Ensino Superior costumam ser ofertados em centros de ensino que concentram grandes grupos de alunos em cada turma e aulas de reforço escolar costumam ser oferecidas em pequenos grupos ou individualmente); segundo o local de moradia dos estudantes (alunos que residem em regiões afastadas de grandes centros tendem a acessar relativamente mais cursos a distância); e segundo a condição social das famílias dos alunos que frequentam essas atividades (em geral, os estudos sobre shadow education indicam que as aulas particulares ou cursos presenciais, geralmente mais caros, são acessados por estudantes cujas famílias detêm mais recursos) (BUCHMANN et al., 2010; BRAY, 2007; STEVENSON; BAKER, 1992).

Tendo em vista a diversidade de formas de participação em atividades suplementares, os estudos sobre o tema geralmente indicam que acessar a informação sobre a participação nessas atividades pelo lado da demanda (por meio da aplicação de questionários a estudantes, muitas vezes associados à realização de avaliações em larga escala) é relativamente mais fácil do que pelo lado da oferta, já que, em muitos casos, não é possível obter informações sobre quantos estudantes frequentam determinado curso em determinada instituição ou sobre a oferta de aulas particulares, por exemplo. A despeito dessa dificuldade, algumas 
pesquisas destacam a expansão das atividades de algumas empresas especializadas na oferta de cursos suplementares. Bray (2013, p. 415) aponta, por exemplo, franquias como a Sylvan, sediada nos Estados Unidos, e a Oxford Learning, sediada no Canadá, como empresas de grande porte dedicadas à oferta de cursos suplementares. Além dessas, o autor destaca a expansão da franquia Kumon, uma das maiores empresas de ensino suplementar do mundo. Originada no Japão em meados da década de 1950, a empresa contava, em abril de 2020, com franquias em mais de cinquenta países, atendendo a mais de 4 milhões de alunos em cursos nas áreas de linguagens e matemática, principalmente ${ }^{1}$.

Em relação às disciplinas ou aos tipos de atividades mais procuradas, estudos conduzidos em diferentes contextos costumam indicar que aulas ou cursos dedicados ao ensino de matemática são geralmente os mais demandados. Além desse ensino, cursos de idiomas e preparatórios para os testes utilizados nas seleções para o ingresso no Ensino Superior são também relatados como frequentes, ainda que a demanda por essas diferentes atividades varie em função das características dos sistemas de ensino de cada contexto e do momento em que os estudantes estão em suas trajetórias escolares (os cursos preparatórios para o ingresso no Ensino Superior, por exemplo, são relativamente mais acessados por estudantes que estão concluindo o Ensino Médio ou que o concluíram recentemente) (CHAN; BRAY, 2014, p. 6; COSTA et al., 2013; BRAY, 2007, p. 34-36; BAKER et al., 2001).

Quanto à escala de participação em atividades de ensino suplementar, as pesquisas costumam relatar certa tendência de expansão generalizada dessas atividades em diversos países (BRAY, 2007, 2011, 2015). De qualquer maneira, as maiores proporções de frequência a algum tipo de atividade suplementar têm sido registradas em Hong Kong, no Japão e na Coréia do Sul. As pesquisas sobre o tema, que proliferam nesses países, registram percentuais de participação em algum tipo de curso suplementar de $70 \%$ entre estudantes do Ensino Médio em Hong Kong (sendo o preparo para testes a principal motivação para a frequência a cursos) (BRAY; KWOK, 2003); 88\% entre os estudantes que pretendem ingressar no Ensino Superior no Japão (STEVENSON; BAKER, 1992, p. 1642-1645); 70\% entre estudantes da educação básica na Coréia do Sul, no ano de 2011 (CHOI; PARK, 2016).

Em relação à motivação de estudantes/famílias que demandam atividades de ensino suplementar, pode-se dizer que tanto a motivação relacionada à compensação ou prevenção do fracasso escolar (p. ex., quando recorrem a aulas de reforço escolar) quanto a que diz respeito às atividades que se somam à experiência escolar do ensino regular (exemplificadas pelos cursos de idiomas ou pelos cursos preparatórios para o ingresso no Ensino Superior, já que esses cursos geralmente não têm como objetivo sanar ou prevenir dificuldades no ensino regular, ainda que possam ter efeitos sobre as atividades desenvolvidas nesse) parecem refletir certa expectativa de que o sucesso escolar possa ser uma via de ascensão social ou de manutenção de posições relativamente privilegiadas no espaço social (BRAY, 2007, 2015, p. 9; BRAY; KWOK, 2003; SOUTHGATE, 2009; BUCHMANN et al., 2010; COSTA et al., 2013; STEVENSON; BAKER, 1992).

Nesse sentido, dado o potencial das atividades de shadow education de garantir vantagens educacionais para estudantes relativamente já privilegiados socialmente (considerando que o acesso a esses cursos depende de um nível mínimo de recursos materiais e simbólicos), os quais já tendem a ter melhores possibilidades de resultados educacionais positivos (COLEMAN, 1966; HANUSHEK, 1997), a maior parte dos estudos sobre shadow education costuma indicar como preocupação central a possibilidade de essas atividades estarem atuando como uma via de manutenção ou aumento de desigualdades escolares entre estudantes de diferentes condições sociais, desigualdades essas que podem ter consequências em termos de possibilidades de acesso a determinados tipos de trabalho e certos níveis de renda (CHOI; PARK, 2016; BRAY, 2003, 2015; BUCHMANN, 2010; SOUTHGATE, 2009; STEVENSON; BAKER, 1992). 
À análise mais objetiva das desigualdades escolares potencialmente produzidas por meio das diferentes possibilidades de acesso a cursos suplementares geralmente escapa, contudo, a complexidade do tema: em um contexto como o brasileiro, por exemplo, a participação de um estudante em um curso de inglês em uma escola de idiomas de baixo custo pode ter significados e consequências muito diferentes da participação de um estudante em um curso de alto custo de inglês (ou qualquer outro idioma). Além disso, a motivação para a participação em determinado curso pode sinalizar muito mais sobre a condição social dos indivíduos do que a própria participação no curso: a realização de um curso de idiomas como meio de preparo para o mercado de trabalho ou como realização de uma atividade julgada interessante ou prazerosa pode indicar maior ou menor dependência do curso em questão para a conquista de posições escolares e/ou sociais relativamente melhores, sendo possível que a motivação para a realização de determinado curso, talvez tanto quanto a realização do curso em si, funcione como elemento de distinção social. Esse tipo de análise, contudo, geralmente requer um tipo de informação difícil de ser produzida, sendo provavelmente por isso que as pesquisas sobre o tema se dedicam ao estudo da participação ou não em um conjunto relativamente agregado de cursos (sendo, por exemplo, comum que as pesquisas tratem de cursos de idiomas, não de cursos segundo o tipo de idioma) e dos efeitos dessa participação sobre os resultados educacionais dos estudantes, sem maior detalhamento sobre as possíveis diferenças existentes entre cursos ou entre as formas como esses cursos são "consumidos".

Tendo por base esse breve diálogo com algumas das possibilidades de análise do tema, conforme abordado pela literatura internacional sobre shadow education, a seção seguinte do artigo trata da literatura que explora informações sobre a participação de estudantes brasileiros em atividades de ensino suplementar.

\section{Ensino Suplementar no Brasil}

A pesquisa que trata da realidade brasileira sobre a participação de estudantes em cursos ou atividades de ensino suplementar é escassa e os poucos trabalhos existentes, frequentemente produzidos por autores portugueses ou em parceria com universidades de Portugal, analisam o tema a partir da aplicação de questionários a pequenas amostras de alunos, geralmente com o propósito de analisar a frequência ou não a determinadas atividades de ensino suplementar (GOMES et al., 2010; COSTA et al., 2013; GOUVEIA; NETO-MENDES, 2014). Dessa maneira, pouco se sabe sobre a dimensão de participação em diferentes modalidades de ensino suplementar no Brasil, tanto no agregado quanto no nível dos estados e municípios.

Além dessas pesquisas (alinhadas à produção internacional sobre mercado das explicações/ shadow education), alguns trabalhos dedicados ao estudo da escolarização das elites, geralmente baseados em entrevistas com indivíduos que podem ser caracterizados como membros de determinada elite $^{2}$, abordam também o tema, ainda que de outra maneira, como será visto adiante.

Costa et al., em análise comparada do mercado das explicações em Brasília, Lisboa, Seul e Ottawa, destacam os cursos preparatórios para o vestibular como relevantes no Brasil. Tendo por base a aplicação de questionários aos alunos que frequentavam aulas em cinco instituições que oferecem ensino suplementar privado em Brasília, os autores verificaram que aproximadamente $47 \%$ dos estudantes buscavam nos cursos frequentados a melhoria do desempenho em vestibulares (COSTA et al., 2013, p. 209). Os resultados foram parecidos com os obtidos entre os alunos de Seul, mas não entre os estudantes de Lisboa e Ottawa, onde $25,6 \%$ e 16,6\%, respectivamente, dos estudantes buscavam preparo para o ingresso no Ensino Superior (COSTA et al., 2013, p. 210). O trabalho destaca ainda a quantidade de tempo que os alunos brasileiros 
dedicam ao ensino suplementar, superior a 20 horas semanais para $30 \%$ dos respondentes (COSTA et al., 2013, p. 211). Os autores concluem que:

[...] a crescente importância que tem sido dada à competição em educação (em particular no que diz respeito à procura dos melhores resultados escolares e à obtenção de lugares nas universidades e nos cursos de maior prestígio) ajuda a explicar o crescimento do número de negócios de reforço escolar em todo o mundo [...]. Este crescimento está diretamente relacionado com a manifesta procura por parte das famílias, cujas expetativas são a obtenção de melhores resultados escolares para os seus filhos e de reforço das probabilidades de sucesso no Ensino Superior e na vida profissional (2013, p. 213).

Em outra pesquisa exploratória sobre o tema, Gomes et al. (2010) analisam a participação dos alunos de $1^{\circ}$ e $3^{\circ}$ anos do Ensino Médio em atividades de ensino suplementar na cidade de Brasília, tendo por base uma amostra de alunos de Ensino Médio de uma escola pública e de uma escola privada. Considerando o total de alunos, o estudo indica que 37,4\% participavam de atividades de reforço escolar, havendo certa concentração em matemática e física $(2013$, p. 8). Os percentuais de participação dos alunos das escolas pública e privada, separadamente, foram de $22 \%$ e $51,9 \%$, respectivamente. A diferença de percentuais de participação em atividades de ensino suplementar, que parece compatível com a distribuição dos capitais cultural e econômico das famílias entre as escolas (sendo possível considerar indicadores de capital cultural e econômico os anos de estudo e as categorias ocupacionais das mães dos alunos: a pesquisa registra que $75,4 \%$ das mães da escola pública tinham como escolaridade máxima a educação básica completa e 61,6\% delas trabalhavam em ocupações manuais, enquanto $78,8 \%$ das mães da escola privada tinham realizado Ensino Superior e 68,5\% das ocupadas em trabalhos não manuais tinham seus filhos matriculados na escola privada) (2013, p. 7), dá indícios do potencial que atividades de shadow education têm para ampliar diferenças educacionais (e diferenças de condições de vida que, porventura, decorram das diferenças educacionais) entre alunos de diferentes condições sociais. Por fim, em relação à motivação dos alunos quanto à participação nas atividades em questão, os autores indicam que "[f]oi unânime a manifestação dos estudantes entrevistados quanto à principal razão que os levou a frequentar aulas de reforço: obter média que lhes permitisse ingressar no curso e instituição de Educação Superior da sua preferência" (2013, p. 8).

As pesquisas citadas ilustram dois tipos de abordagem frequentes nos estudos dedicados à análise da demanda por ensino suplementar: 1) pesquisas que procuram delimitar os fatores associados à frequência dos alunos nesses cursos; ou seja, que indicam as características dos indivíduos e de suas famílias que estão associadas à participação em cursos suplementares, como determinado nível de renda, sexo, cor e escolaridade dos pais (STEVENSON; BAKER 1992; BRAY; KWOK, 2003; SOUTHGATE, 2009;); e 2) estudos que procuram investigar as motivações de alunos e de suas famílias por trás da demanda por ensino suplementar, como o interesse em aulas de reforço associado à necessidade de acompanhar as atividades escolares no ensino regular, em aulas de idiomas que serão úteis para uma futura alocação profissional, ou em preparo relacionado à competição por vagas escassas em cursos disputados no Ensino Superior (NETO, 2006; AZEVEDO, 2011).

Outra abordagem de pesquisa que tem tratado da participação de estudantes em atividades de ensino suplementar no contexto brasileiro (ainda que de forma menos direta do que os estudos anteriormente citados) é a que se dedica à investigação das trajetórias escolares de alunos caracterizados como membros de determinada elite. Nogueira (2004), analisando as estratégias educativas de 25 famílias de grandes e médios(as) empresários(as) (a pesquisa teve por base entrevistas realizadas com os jovens e suas mães), aponta que, 
ao contrário do que seria esperado, o sucesso escolar não é a regra entre tais estudantes. Nos casos considerados na pesquisa, observou-se que o acesso a recursos econômicos não estava necessariamente relacionado a bons resultados escolares. Além disso, nota-se que tanto os jovens quanto suas famílias não perecem contar com a formação escolar para viabilizar as trajetórias profissionais pretendidas. Conforme os relatos recolhidos, os certificados escolares parecem ser entendidos mais como modo de legitimar uma posição a ser ocupada, mais ou menos pré-definida, do que como meio para alcançar determinada posição social (NOGUEIRA, 2004, p. 142-143). De qualquer maneira, buscando contar com o aval da escola para o acesso a posições profissionais/sociais a serem ocupadas, as famílias lançam mão de estratégias que possam corrigir ou compensar trajetórias escolares em desacordo com o que se pretende. Tratando do momento relativo ao ingresso no Ensino Superior, o estudo indica que tais estratégias se materializam tanto na busca por instituições de ensino pouco exigentes ou menos seletivas (NOGUEIRA, 2004, p. 137) quanto "mediante o auxílio largamente utilizado dos 'cursinhos" (NOGUEIRA, 2004, p. 136, grifo nosso).

Brandão e Lellis (2003), em análise da escolarização dos filhos de elites acadêmicas, também fazem referência à demanda de ensino suplementar por parte dessas famílias. Tendo por base a aplicação de questionários e a realização de entrevistas com professores(as) de uma universidade privada do Rio de Janeiro, todos(as) com filhos entre 7 e 17 anos, as autoras procuram delimitar o perfil socioeconômico e cultural dessas famílias e a maneira como pais e filhos se envolvem com aspectos relativos à educação escolar. Entre outros resultados, a pesquisa aponta que os pais/ professores indicaram não ter grandes expectativas em relação ao trabalho das escolas de seus filhos, mas que a familiaridade com o ambiente escolar/acadêmico - viabilizada pelas experiências desses pais/professores em suas próprias trajetórias educativas - contribui para que o acompanhamento da escolarização dos filhos seja eficiente no sentido de "acionar estratégias corretivas e mesmo preventivas em face do primeiro sinal de risco de insucesso, como é o caso da aula particular, prática a que recorrem esses pais com muita frequência" (BRANDÃO; LELLIS, 2003, p. 519, grifo nosso). Ainda em relação a práticas que podem ser caracterizadas como ensino suplementar, as autoras indicam que:

[...] os filhos desenvolvem uma série de atividades extraescolares - esportes, línguas estrangeiras, artes... Todos os entrevistados sem exceção afirmam que pagam cursos fora do horário escolar, mesmo para os filhos que estudam em escolas de tempo integral ou de jornadas mais extensa, como são as escolas bilíngues, caso de quatro entrevistados. Se, à primeira vista, essas atividades podem estar representando uma estratégia educativa de valorização da cultura livre de que fala Bourdieu, e certamente estão, expressam também um poderoso instrumento de conhecimento - reconhecimento - distinção (BRANDÃO; LELLIS, 2003, p. 520).

Em linha com o exposto até aqui, as informações disponíveis sobre a participação de estudantes brasileiros em atividades de ensino suplementar parecem indicar certa tendência de associação entre a condição social de estudantes e suas famílias e a participação em cursos suplementares. Sugerem, também, a possibilidade de que, a depender dos recursos disponíveis, esses frequentem mais de um tipo de curso. Diante disso, a análise empírica preocupou-se em compreender, a partir dos dados do ENEM de 2008, se é possível identificar padrões de frequência a cursos, segundo a condição social dos estudantes e de suas famílias, bem como se a frequência a determinado curso guarda correspondência com a participação em outros tipos de cursos suplementares. 


\section{Ensino Suplementar e Capitais Econômico e Cultural}

Em linhas gerais, pode-se dizer que os estudos tratados na seção anterior indicam que diferentes modalidades de ensino suplementar podem ser procuradas ou não por indivíduos/famílias com diferentes características, a partir de diferentes motivações. Algumas motivações estariam mais associadas à compensação de defasagens escolares no ensino regular, enquanto outras tenderiam a ter relação com a percepção de que são desejáveis experiências educativas adicionais às experimentadas no ensino regular - talvez como forma de diferenciação educacional em um contexto de expansão/universalização do ensino regular ou, de modo mais geral, como meio de compensação de um ensino regular percebido como insuficiente, tendo em vista determinados parâmetros ou objetivos (educacionais, profissionais ou, mais amplamente, atrelados a condições e/ou estilos de vida pretendidos ou esperados) a serem alcançados. Essas diferentes motivações, combinadas com diferentes condições sociais, das quais podem ser, em alguma medida, produto, tendem a dar origem a diferentes linhas de ação em relação à participação em cursos de ensino suplementar.

Diante do exposto, tendo por base elementos da análise bourdieusiana que tratam das relações entre o espaço social e as práticas dos indivíduos (sobretudo em A Distinção [BOURDIEU, 2017]), seria possível sugerir que diferentes combinações de volume de capital econômico e cultural poderiam estar na origem de diferentes estratégias de participação em cursos de ensino suplementar. Em um extremo, estariam indivíduos que, talvez acumulando exclusões em experiências diversas de socialização (no ensino regular, inclusive), podem ter poucas possibilidades de se apropriar dos sentidos (sociais) associados à realização de diferentes tipos de atividades de ensino suplementar, assim como podem não ter condições de pagar por esses cursos. No outro extremo estariam indivíduos/famílias que teriam boas possibilidades de se apropriar simbólica e materialmente de uma quantidade significativa de modalidades/tipos de cursos suplementares. Entre esses dois grupos, diferentes combinações possíveis de capital cultural e econômico influenciariam a demanda por diferentes tipos de cursos.

As diferentes combinações possíveis de capitais, contudo, influenciariam a participação em diferentes tipos de curso, não somente tornando possível o acesso a eles, mas também por meio de um ajuste das práticas a disposições socialmente constituídas. Ou seja, as diferentes combinações possíveis de capitais econômico e cultural estariam na origem de diferentes expectativas e motivações em relação às trajetórias educativas a serem seguidas ou em relação a trajetórias educativas desejadas ou entendidas como desejáveis. Nesse sentido, nem todo curso que pode ser acessado (tendo em vista os recursos disponíveis) seria acessado, mas somente os cursos suplementares que refletem o ajuste da trajetória educacional às condições de existência dos indivíduos.

Considerando os apontamentos da literatura e a possibilidade de existência de relações entre as diferentes composições de capitais e as práticas de ensino suplementar, analisamos, nas próximas seções, os dados do ENEM 2008 que tratam de algumas atividades de ensino suplementar entre os estudantes que participaram do exame naquele ano. Para tanto, esses dados foram submetidos à Análise de Correspondências Múltiplas (ACM). Na sessão seguinte do artigo são apresentadas tanto a abordagem metodológica seguida quanto as variáveis e bases de dados utilizadas na análise.

\section{Análise de Correspondências Múltiplas Aplicada aos Dados do ENEM 2008}

Poucas bases de dados no Brasil trazem informações sobre a participação de estudantes em cursos suplementares. Talvez isso se dê pela percepção de que a frequência nessas atividades não seja relevante no 
conjunto da população brasileira; talvez porque não sejam claras as relações entre a participação em tais atividades e suas consequências (escolares, profissionais, relativas a desigualdades futuras de condições de vida etc.); ou talvez porque o levantamento desse tipo de informação, em larga escala, envolva certo custo.

Entre as bases de dados existentes, a relativa ao questionário socioeconômico do ENEM 2008 é uma das mais completas, ainda que não traga detalhes sobre as atividades frequentadas. Além de diversas questões que procuram caracterizar o perfil socioeconômico dos estudantes que realizaram o exame, os itens 79 a 84 pedem que o inscrito fale sobre "a(s) atividade(s) ou o(s) curso(s) que você realiza ou realizou fora da sua escola durante o Ensino Médio ( $2^{\circ}$ grau)", da seguinte maneira (Tabela 1$)$ :

Tabela 1. Questões sobre atividades suplementares do ENEM 2008.

\begin{tabular}{lll}
\hline & Sim & Não \\
\hline 79. Curso de língua estrangeira & (A) & (B) \\
\hline 80. Curso de computação ou Informática & (A) & (B) \\
\hline 81. Curso preparatório para o vestibular (cursinho) & (A) & (B) \\
\hline 82. Artes plásticas ou atividades artísticas em geral & (A) & (B) \\
\hline 83. Esportes, atividades físicas & (A) & (B) \\
\hline 84. Outros & (A) & (B) \\
\hline
\end{tabular}

Fonte: Questionário socioeconômico - Manual do Inscrito 2008 - ENEM 2008 - INEP/MEC.

Como é possível notar, a falta de detalhes sobre tipos de conteúdo, a falta de definição acerca de os cursos ou atividades serem ou não pagos e a pouca precisão, especialmente dos itens 82 e 83, limitam as possibilidades de análise dos dados. Por outro lado, as informações foram coletadas em um exame que atinge, majoritariamente, a faixa etária de interesse, levando em conta a intenção de explorar as práticas relativas ao ensino suplementar entre jovens e adolescentes que guardem proximidade (no quesito tempo) com a experiência no ensino regular.

Para a ACM, foram selecionadas variáveis relativas aos itens 79 a 82 . A exclusão do item 83 , que diz respeito à participação em atividades ou cursos que envolvam esportes ou atividades físicas, deu-se por o item ser pouco preciso, uma vez que, no Brasil, é comum a prática de esportes fora do contexto de cursos. Como o enunciado que precede os itens deixou a possibilidade de realização de "atividades ou cursos" e o item não adiciona especificação alguma, foi excluído da análise. O item 84 foi excluído porque seria difícil analisar o significado de qualquer associação entre a variável "outros" e as demais.

Em relação a cursos de informática e atividades ou cursos ligados a artes, a escolha por mantê-los na análise se deu porque: 1) em uma análise exploratória sobre características do ensino suplementar a partir de uma grande base de dados como o ENEM, entendemos ser válida a consideração do maior número possível de tipos de cursos/atividades, dada a possibilidade de conhecer as taxas de frequência de cada um; 2) essas atividades encontram correspondentes no ensino regular, podendo ter consequências sobre a aprendizagem e sobre oportunidades educacionais dos alunos; e 3) como frequentemente ocorre com atividades consideradas shadow education em outros contextos, esses cursos podem ter consequências em termos de vantagens futuras no Ensino Superior ou na vida profissional dos indivíduos.

No que diz respeito ao universo a ser analisado, a opção foi trabalhar apenas com os dados dos estudantes que realizaram sua inscrição no exame no estado de São Paulo (que contou com aproximadamente $26 \%$ das inscrições do ENEM 2008). A escolha por apenas um estado foi feita porque a existência de diferentes 
realidades no ensino regular e a diversidade de aspectos no que diz respeito ao exercício de atividades profissionais podem implicar características distintas de participação em atividades de ensino suplementar em diferentes localidades, assim como podem se refletir em diferentes padrões de relação entre os cursos frequentados e a condição social das famílias. Dessa maneira, a opção foi restringir a análise a um contexto relativamente homogêneo no que diz respeito aos macrofatores que pudessem afetar a participação dos estudantes em cursos suplementares.

Ainda em relação ao universo considerado, a opção foi tomar como base o total de respondentes dos questionários, não somente os concluintes e recém-egressos do Ensino Médio. Essa escolha foi feita pois o texto do questionário socioeconômico que introduzia os itens relativos à participação ou não em cursos suplementares solicitava que os respondentes tratassem da participação em cursos suplementares durante o Ensino Médio ${ }^{3}$. Assim, mesmo no caso dos participantes do exame que não eram concluintes ou recémegressos dessa modalidade de ensino, o relato das experiências relativas a cursos suplementares remonta ao momento em que o ele foi cursado.

Sendo assim, foram submetidos à ACM os dados dos inscritos no estado de São Paulo referentes aos itens 79 a 82, com o acréscimo de outras variáveis categóricas, relativas aos itens do questionário que indicam a dependência administrativa da escola em que o Ensino Médio foi cursado (item 77 do questionário socioeconômico), a renda familiar (item 23) e a escolaridade dos pais (itens 17 e 18). Essas duas últimas variáveis, tratadas aqui como indicadores de capital econômico (item 23) e cultural (itens, 17 e 18), inseridas como variáveis suplementares, permitirão a identificação ou não de relações entre a realização de determinados cursos e as faixas de renda familiar, assim como entre a participação nos cursos e os anos de estudo dos pais dos estudantes inscritos no exame.

No que diz respeito à $\mathrm{ACM}$, pode-se dizer que a técnica é útil para a análise da interdependência entre variáveis categóricas e entre as categorias dessas variáveis (FÁVERO; BELFIORE, 2017). Em linhas gerais, pode-se dizer que a análise de correspondências permite que a relação entre variáveis e suas categorias, tendo por base tabelas cruzadas de dados (que indicam frequências de ocorrência de cada cruzamento), seja transposta em termos de coordenadas em um gráfico (GREENACRE, 2008). As categorias que guardam maior relação entre si tendem se agrupar em determinado espaço do gráfico. Dessa maneira, é possível analisar, por meio das distâncias relativas entre pontos relacionados a diferentes categorias, o quanto elas se associam ou se opõem, representando, ao mesmo tempo, homologias e distinções.

Tendo em vista os dados indicados e a abordagem metodológica a ser seguida, são apresentados, na próxima sessão, uma descrição geral dos dados de participação em cursos ou atividades suplementares no estado de São Paulo e os resultados da análise de correspondências.

\section{Resultados da ACM}

Entre os inscritos no ENEM 2018 no estado de São Paulo, a maioria era do sexo feminino (59\%), aproximadamente $80 \%$ tinha até 23 anos (entre os que informaram a data de nascimento) e a maioria se declarou branco (38\%, relativamente a $18 \%, 6 \%$ e $1,8 \%$ que se declararam pardos, pretos e amarelos, respectivamente, considerando os que responderam a esse item).

No que diz respeito à participação nos cursos ou atividades fora da escola durante o Ensino Médio (Tabela 2), levando em conta somente os alunos que responderam ao questionário socioeconômico ${ }^{4}$ e que responderam aos itens que tratam dos cursos em questão, merece destaque a participação em cursos de informática, com $55 \%$ de respostas afirmativas. No outro extremo, são as atividades ou cursos de artes 
os menos frequentes entre os estudantes que participaram do ENEM 2008. Os cursos preparatórios para exames de ingresso no Ensino Superior, com 14\% de participação entre os respondentes, provavelmente apresentariam outra dimensão de valores se a questão não se restringisse a verificar os cursos realizados durante o Ensino Médio.

Ainda que a leitura dos dados deva ser feita com cautela, já que o ENEM não é uma amostra representativa da população com idade equivalente à dos concluintes e recém-egressos do Ensino Médio, é razoável supor que, além de cursos de idiomas e preparatórios para o vestibular, ao menos em 2008, cursos de informática eram relevantes no que diz respeito ao ensino suplementar no contexto considerado.

Tabela 2. Participação em cursos ou atividades suplementares no ENEM 2008 - SP.

\begin{tabular}{lccccccc}
\hline \multirow{2}{*}{ Cursos/atividades } & \multicolumn{2}{c}{ Sim } & & \multicolumn{2}{c}{ Não } & & Total \\
\cline { 2 - 3 } & Frequência & Perc. & & Frequência & Perc. & Frequência \\
\hline Curso de língua estrangeira & 192.431 & $28 \%$ & & 484.896 & $72 \%$ & 677.327 \\
\hline Curso de computação ou informática & 369.843 & $55 \%$ & & 307.617 & $45 \%$ & 677.460 \\
\hline Curso preparatório para o vestibular (cursinho) & 96.203 & $14 \%$ & & 577.998 & $86 \%$ & 674.201 \\
\hline Artes plásticas ou atividades artísticas em geral & 69.065 & $10 \%$ & 605.114 & $90 \%$ & 674.179 \\
\hline Esportes, atividades físicas & 258.348 & $38 \%$ & & 418.554 & $62 \%$ & 676.902 \\
\hline Outro curso & 203.274 & $30 \%$ & 469.605 & $70 \%$ & 672.879 \\
\hline
\end{tabular}

Fonte: Elaboração própria, com base nos dados do ENEM 2008 - INEP.

Para a análise relacional da informação sobre a participação dos alunos nos diferentes cursos, foram realizados três diferentes exercícios de análise de correspondências. No primeiro deles (Fig. 1), foram incluídas as variáveis relativas aos cursos suplementares e a variável que diz respeito à dependência administrativa das escolas em que os alunos estudaram no Ensino Médio (pública ou privada), todas como ativas (variáveis utilizadas para a construção dos eixos do gráfico). Nos demais exercícios, foram incluídas, como variáveis suplementares (variáveis projetadas nos gráficos, mas que “[...] não interferem no cálculo das distâncias relativas e na orientação dos eixos" [BERTONCELO, 2016, p. 5]), a renda familiar (indicador de capital econômico) e a escolaridade do pai (indicador de capital cultural) dos estudantes considerados na análise (Figs. 2 e 3, respectivamente).

Como pode ser visto na Fig. 1, é possível verificar, no primeiro eixo (ou dimensão 1), uma polarização entre os alunos que frequentaram escolas particulares, cursos de idiomas, pré-vestibular e de artes e os que não frequentaram cursos suplementares e estudaram em escolas públicas no Ensino Médio. A proximidade do centro dos eixos indica a maior frequência relativa dos que não frequentaram cursos suplementares e dos que estudaram em escolas públicas, enquanto a maior distância do centro dos eixos aponta o potencial de distinção dos cursos de artes e das escolas particulares, principalmente. Além disso, as distâncias entre as categorias revelam certa associação entre a participação em cursos preparatórios para o vestibular e a participação em cursos ou atividades de artes, relativamente às demais combinações possíveis de participação em cursos suplementares.

Talvez a informação mais relevante, contudo, seja a revelada pela leitura conjunta dos dois eixos (ou dimensões) ${ }^{5}$. O segundo eixo, que aponta a oposição entre os que frequentaram cursos de informática e os que não frequentaram esse tipo de curso, revela que a participação em cursos de informática não está associada à participação em outros cursos, mas indica, também, que não há associação significativa entre a não participação em cursos de informática e a não participação nos demais cursos. Sobre esse ponto, talvez seja possível formular a hipótese de que o primeiro eixo (dimensão 1) trata, principalmente, de práticas de ensino suplementar associadas a um preparo voltado para vivências (escolares e/ou profissionais e/ou associadas 
a determinado estilo de vida a ser mantido ou alcançado) cujos efeitos estão, essencialmente, em médio e longo prazos (não associados a uma necessidade imediata de retornos), enquanto o segundo eixo (dimensão 2) diz respeito, sobretudo, a um tipo de aprendizado que pode ter aplicações profissionais mais imediatas, prevalecendo certo aspecto instrumental dos cursos - o que estaria associado a estratégias típicas de frações de classe que têm preocupações de curto prazo em relação ao retorno, em termos de ganho no mercado de trabalho.

De qualquer maneira, ainda que sejam necessárias outras abordagens de pesquisa para um entendimento melhor dos padrões observados, a leitura conjunta da informação parece indicar que as práticas consideradas, em termos de participação em cursos suplementares, revelam algo sobre a estrutura do espaço dos estilos de vida, ou sobre a estrutura das posições dos estudantes e de suas famílias no espaço social. As Figs. 2 e 3, que incorporam indicadores relativos às condições sociais das famílias como variáveis suplementares, permitem que se avance na análise.

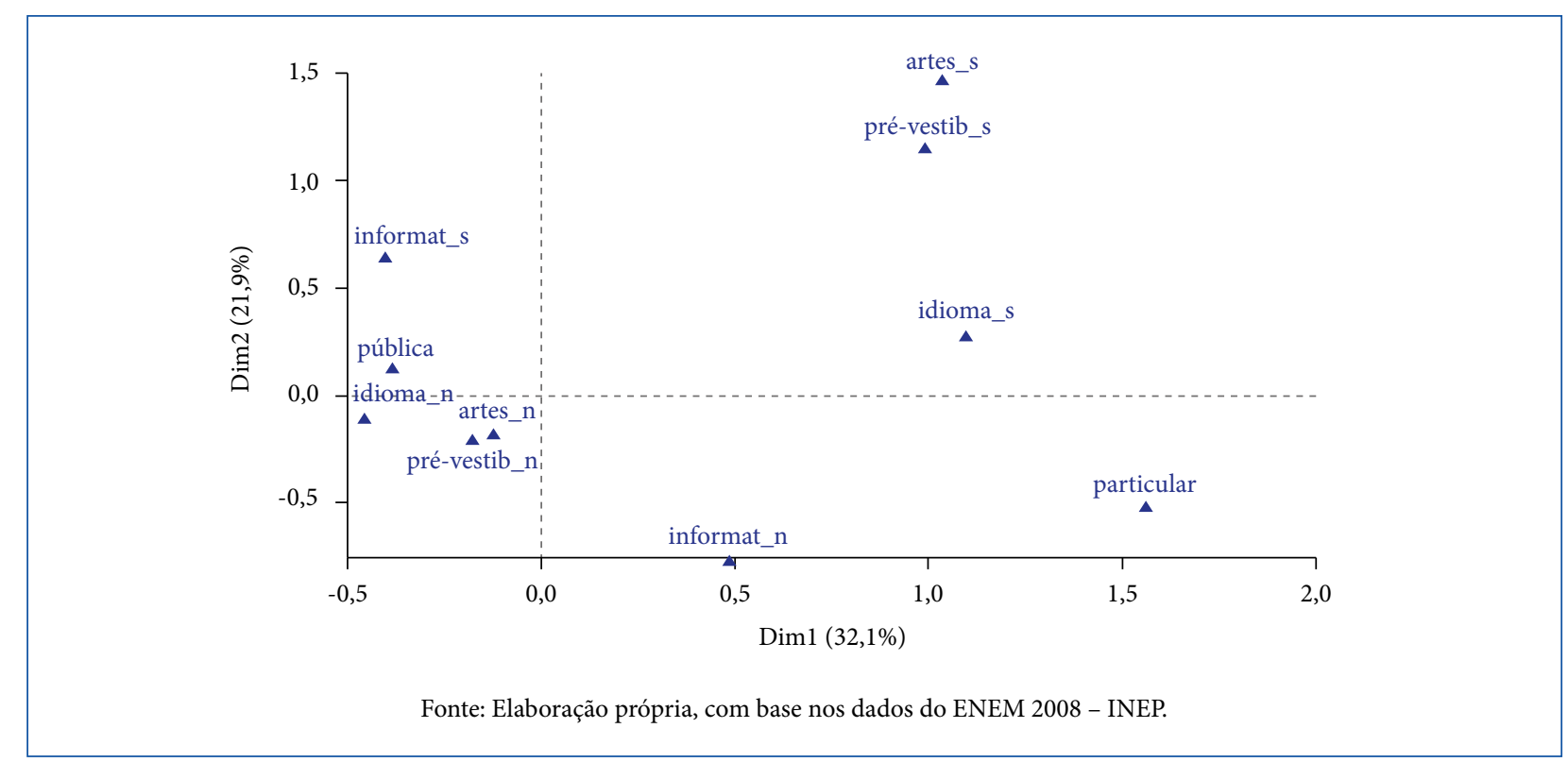

Figura 1. Mapa perceptual das categorias relativas aos cursos ou atividades suplementares - ENEM 2008 - SP.

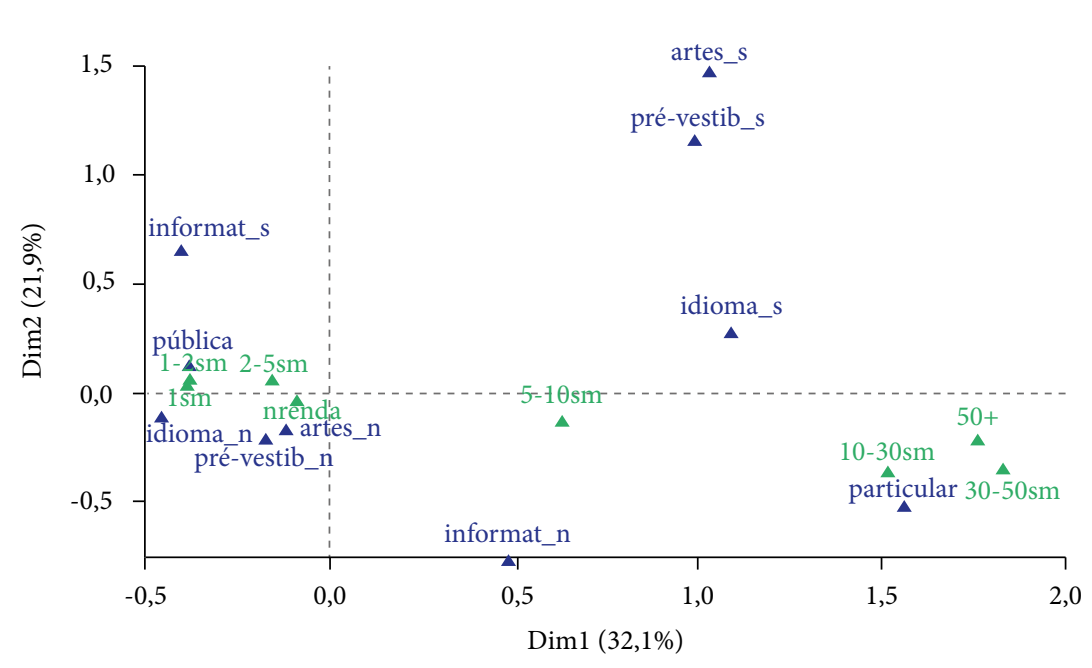

Fonte: Elaboração própria, com base nos dados do ENEM 2008 - INEP.

Figura 2. Mapa perceptual das categorias relativas aos cursos ou atividades suplementares, com sobreposição de categorias de renda familiar - ENEM 2008 - SP. 


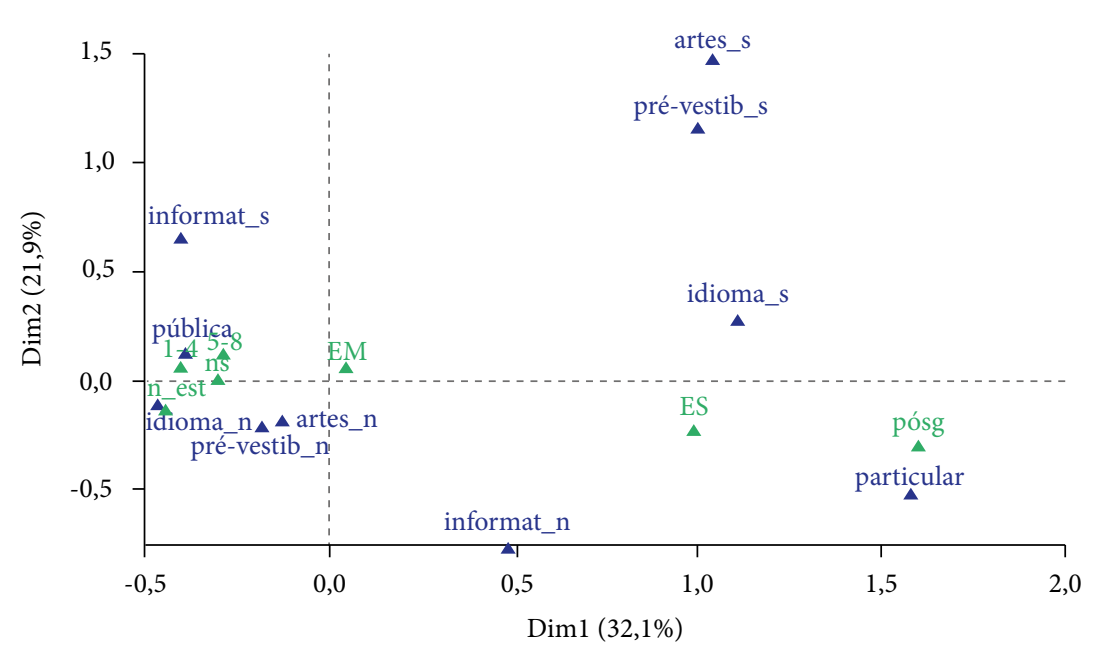

Fonte: Elaboração própria, com base nos dados do ENEM 2008 - INEP.

Figura 3. Mapa perceptual das categorias relativas aos cursos ou atividades suplementares, com sobreposição de categorias de escolaridade do pai - ENEM 2008 - SP.

Como é possível notar (Figs. 2 e 3), as variáveis relativas a renda familiar e escolaridade dos pais apresentam distribuição similar, revelando uma já esperada associação entre rendimentos e escolaridade. Além disso, nota-se que: 1) há algum grau de correspondência entre a condição social dos indivíduos e a participação ou não em cursos suplementares: enquanto menores níveis de renda e escolaridade se associam à não participação em cursos de idiomas, artes e pré-vestibulares, maiores níveis de renda e escolaridade guardam alguma relação com a realização de cursos, sobretudo de idiomas; e 2) o padrão de participação em cursos se inverte quando se trata de cursos de informática, estando a participação neles associada a renda e escolaridade menores, relativamente a renda e escolaridade dos pais dos que não os frequentam, o que sugere que a não realização de cursos de informática pode não estar associada à falta de condições de apropriação desses cursos.

As Figs. 4 e 5 ilustram, de outra maneira, a correspondência entre a condição social dos alunos e a participação em atividades de ensino suplementar. Pode-se notar que os percentuais de participação nos cursos de artes, idiomas e pré-vestibulares crescem conforme aumentam a renda familiar e os anos de estudo dos pais dos estudantes, ocorrendo o contrário no caso dos cursos de informática. Vale notar, também, que a mudança de patamar de participação ou não nos cursos fica clara na faixa de dez a trinta salários mínimos ou quando os pais dos alunos cursaram Ensino Superior. Além disso, pode-se dizer que a mudança de faixa de renda de trinta a cinquenta salários mínimos para mais de cinquenta não implica mudança significativa nos percentuais de participação nos cursos considerados na pesquisa, comportamento diferente do observado no caso das faixas superiores de escolaridade dos pais dos estudantes: nota-se aumento significativo da participação, especialmente em cursos de idiomas, quando se passa da análise dos pais com curso superior para os pais que fizeram pós-graduação.

Tendo em vista a distribuição da participação dos estudantes segundo os indicadores de capital econômico e cultural considerados, pode-se dizer que, ao menos entre os inscritos no ENEM 2008, no estado de São Paulo, há concentração relativa da realização de cursos entre as maiores faixas de renda e de anos de estudo dos pais dos alunos. Ao que parece, indivíduos/famílias com condições de arcar com altas despesas no ensino regular optam por participar de atividades de ensino suplementar no contexto considerado. 
Os resultados indicam que é possível identificar, em alguma medida, tanto homologias e distinções no que diz respeito à participação em cursos suplementares entre os estudantes que participaram do ENEM 2008 quanto certa associação entre as condições sociais desses estudantes e os padrões de participação ou não nos cursos em questão. Esses padrões observados - os quais indicam que a frequência a determinado curso tanto guarda correspondência com a participação em outros cursos (a relação entre a participação em cursos de artes e preparatórios para o vestibular é a que mais se destaca nesse caso) quanto com a não participação em outros cursos (a relação entre a participação em cursos de idiomas e a não participação em cursos de informática é a que mais se destaca nesse caso) - sugerem que os estudantes e/ou as suas famílias demandam atividades de ensino suplementar ajustadas a possibilidades, motivações e expectativas socialmente constituídas, no tocante às trajetórias educacionais a serem seguidas.

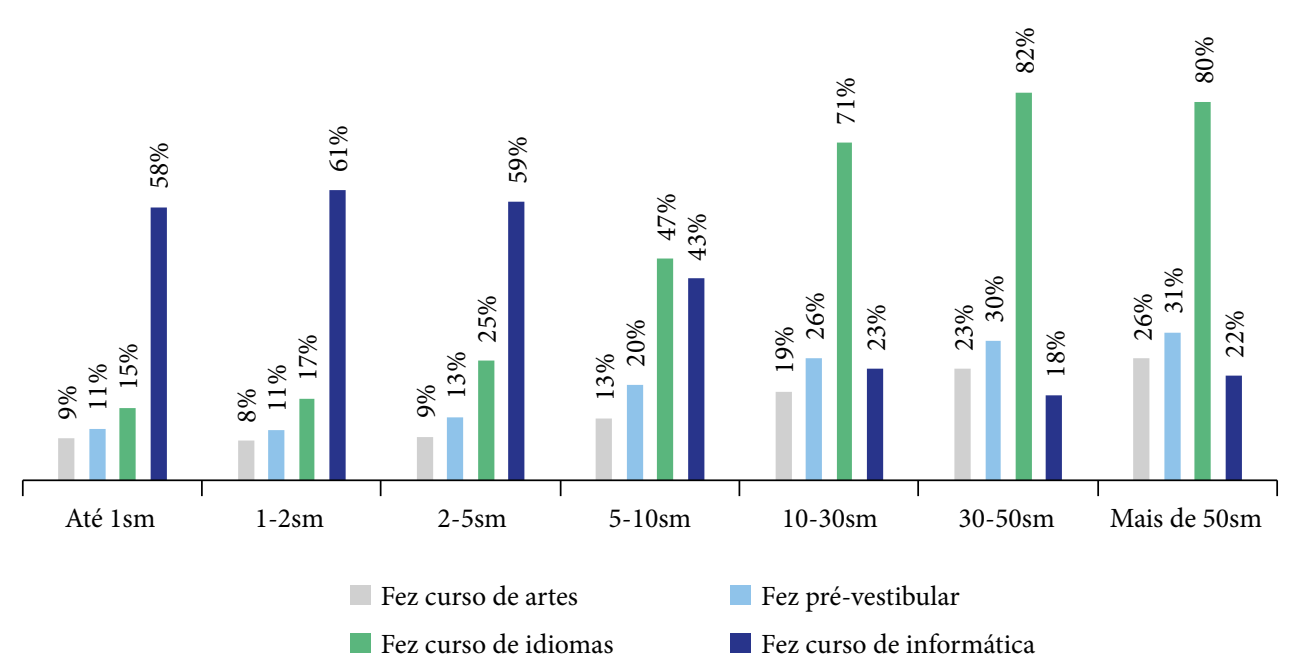

Fonte: Elaboração própria, com base nos dados do ENEM 2008 - INEP.

Figura 4. Percentual de participação em cursos suplementares, segundo a renda familiar.

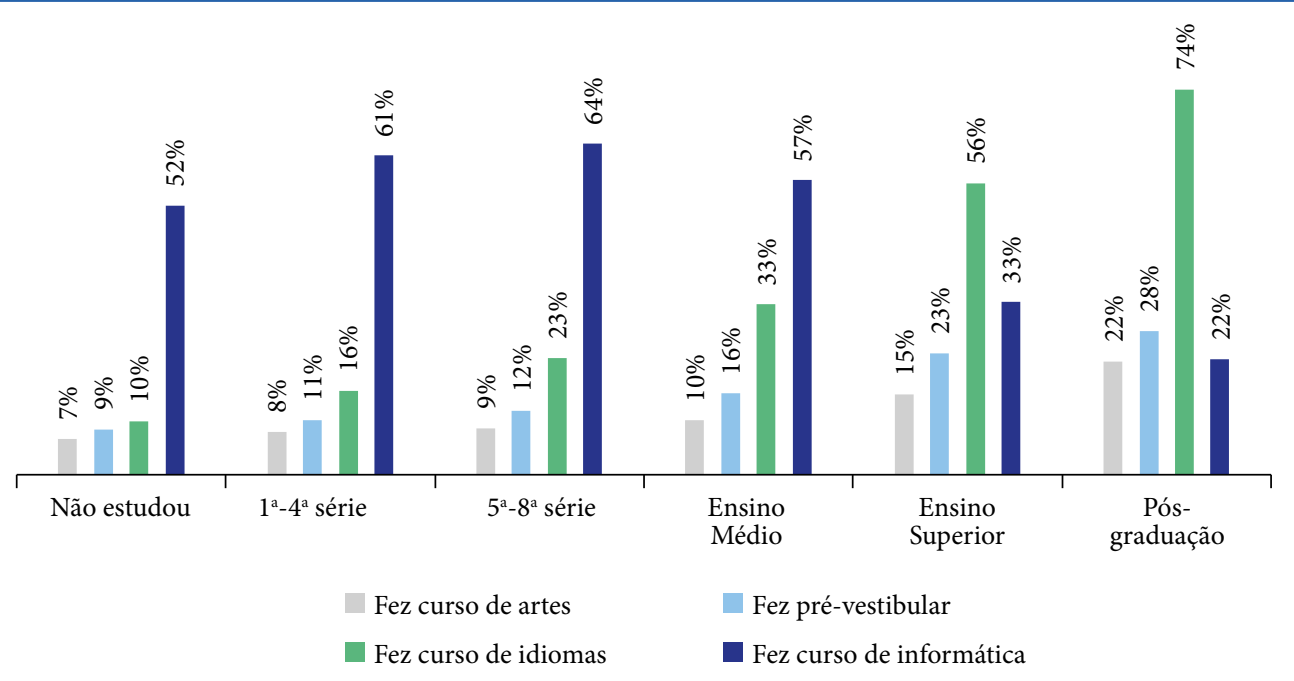

Fonte: Elaboração própria, com base nos dados do ENEM 2008 - INEP.

Figura 5. Percentual de participação em cursos suplementares, segundo a escolaridade do pai. 


\section{Considerações Finais}

Pesquisas conduzidas em diferentes contextos têm apontado a expansão de práticas de ensino suplementar. Esses cursos, ofertados à parte do ensino regular oferecido por escolas públicas ou privadas, somam-se às oportunidades de aprendizagem ou experiências educativas vividas por crianças e jovens no ensino regular e podem ter consequências em termos de vantagens educacionais e/ou profissionais para aqueles que podem acessá-los.

Tentado dialogar com as poucas pesquisas sobre o assunto no contexto brasileiro, procuramos explorar o tema segundo uma aproximação com elementos da teoria bourdieusiana que tratam das relações entre as práticas dos indivíduos e as posições ocupadas por eles no espaço social. Fazendo uso da técnica de Análise de Correspondências Múltiplas, buscamos verificar a existência ou não de padrões de participação em cursos suplementares a partir da base de dados relativa ao questionário socioeconômico dos alunos do ENEM 2008. Além disso, foi explorada a existência ou não de associação entre os padrões observados de participação nos cursos e variáveis representativas das condições sociais dos alunos (a renda familiar dos alunos foi tomada como indicador de capital econômico e a escolaridade do pai foi tomada como indicador de capital cultural dos estudantes).

Os resultados indicaram que as práticas dos indivíduos, em termos de participação em cursos ou atividades de ensino suplementar, apresentam certo padrão, sendo possível destacar que os alunos que fizeram Ensino Médio em escolas públicas tendiam a não frequentar cursos de idiomas, artes e pré-vestibulares, mas sim a ter maior participação em cursos de informática em relação aos alunos que cursaram Ensino Médio em escolas particulares. Além disso, a projeção das variáveis suplementares indicativas dos capitais econômico e cultural das famílias dos alunos revelou que há certa associação entre a condição social dos estudantes considerados e os tipos de curso suplementar frequentados ou não.

Nesse sentido, é possível apontar que a participação nesses cursos tende a estar ajustada às condições de vida dos alunos e de suas famílias - a diferença de padrões observados entre os cursos de informática e os demais cursos, por exemplo, parece confirmar esse ajuste das práticas às posições ocupadas no espaço social. Dito de outra maneira, parece plausível supor que diferentes combinações de capital econômico e cultural estejam associadas a diferentes possibilidades e motivações em relação à participação nos cursos suplementares considerados e que estas possibilidades e motivações diferentes tendam a originar diferentes linhas de ação em relação à participação em cursos suplementares.

\section{Notas}

1. Disponível em: http://www.kumongroup.com/eng/world/. Acesso em: 28 fev. 2019.

2. Foge ao escopo deste artigo tratar do debate sobre definições possíveis de elite. Em linha com Hey, adota-se o termo "elites" (no plural), considerando que: "[a] apreensão das elites de modo multidimensional, a partir da descrição e interpretação da composição de diferentes espécies de capital em relação ao valor que eles assumem em determinadas sociedades ou jogos institucionais, pode permitir a distinção entre as elites ou frações de elites, como por exemplo entre elites intelectuais, econômicas, políticas, artísticas" (2017, p. 2).

3. O texto do questionário socioeconômico do ENEM de 2008 solicitava que fossem indicadas "a(s) atividade(s) ou o(s) curso(s) que você realiza ou realizou fora da sua escola durante o Ensino Médio ( $2^{\circ}$ grau)”. Disponível em: http://portal.mec.gov.br/arquivos/pdf/manual_questionario.pdf. Acesso em: 12 abr. 2020. 
4. Apenas 65\% dos que fizeram a inscrição do ENEM de 2008 em São Paulo responderam ao questionário socioeconômico.

5. Conforme Greenacre (2008), devem ser plotadas no mapa perceptual somente as dimensões que apresentam valores de inércia parcial superiores à média da inércia principal total por dimensão. No caso em questão, em que Inércia Total $=(10-5) / 5=1$ e Média da Inércia Principal Total $=1 /(10-5)=0,2$, duas dimensões foram consideradas no mapa, já que somente as duas primeiras dimensões apresentaram Inércia Parcial superior a 0,2.

\section{Referências}

AZEVEDO, S. M. M. A actividade das explicações: Um estudo no ensino secundário e superior. 2011. Tese (Doutorado em Ciências da Educação) - Departamento de Ciências da Educação, Universidade de Aveiro, Aveiro, 2011.

BAKER, D. P. et al. Worldwide shadow education: Outside-school learning, institutional quality of schooling, and cross-national mathematics achievement. Educational Evaluation and Policy Analysis, v. 23, n. 1, p. 1-17, Sep. 2001. https://doi.org/10.3102/01623737023001001

BERTONCELO, E. O uso da Análise de Correspondências Múltiplas nas Ciências Sociais: Possibilidades de aplicação e exemplos empíricos. In: Anais do 40 Encontro Anual da ANPOCS, Caxambu, 2016.

BOURDIEU, P. Escritos de educação. 14. ed. Petrópolis: Vozes, 2013.

BOURDIEU, P. A distinção: Crítica social do julgamento. 2. ed. Porto Alegre: Zouk, 2017.

BRANDÃO, Z.; LELLIS, I. Elites acadêmicas escolarização dos filhos. Educação \& Sociedade, Campinas, v. 24, n. 83, p. 509-526, ago. 2003. http://doi.org/10.1590/S0101-73302003000200011

BRAY, M. Adverse effects of private supplementary tutoring: Dimensions, implications and government responses. Paris: Unesco, 2003.

BRAY, M. The shadow education system: Private tutoring and its implications for planners. Paris: Unesco, 2007.

BRAY, M. The challenge of shadow education: Private tutoring and its implications for policy makers in the European Union. Network of Experts in Social Sciences of Education and training (NESSE), 2011.

BRAY, M. Exacerbating or reducing disparities? The global expansion of shadow education and implications for the teaching profession. International Council on Education for Teaching (ICET), $\mathbf{5 9}^{\text {th }}$ World Assembly, “Challenging Disparities in Education”, Naruto University of Education, Japan, 2015. Disponível em: https://hub.hku.hk/bitstream/10722/222068/1/Content.pdf. Acesso em: 10 abr.2020.

BRAY, M.; KWOK, P. Demand for private supplementary tutoring: Conceptual considerations, and socioeconomic patterns in Hong Kong. Economics of Education Review, n. 22, p. 611-620, 2003. https://doi. org/10.1016/S0272-7757(03)00032-3

BUCHMANN, C.; CONDRON, D. J.; ROSCIGNO, V. J. Shadow education, American style: Test preparation, the SAT and college enrollment. Social Forces, v. 89, n. 2, p. 435-461, dez. 2010. https://doi.org/10.1353/ sof.2010.0105 
CHAN, C.; BRAY, M. Marketized private tutoring as a supplement to regular schooling: Liberal Studies and the shadow sector in Hong Kong secondary education. Journal of Curriculum Studies, v. 46, n. 3, p. 361388, 2014. https://doi.org/10.1080/00220272.2014.883553

CHOI, Y.; PARK, H. Shadow education and educational inequality in South Korea: Examining effect heterogeneity of shadow education on middle school seniors' achievement test scores. Research in Social Stratification and Mobility, v. 44, p. 22-32, 2016. https://doi.org/10.1016/j.rssm.2016.01.002

COLEMAN, J. S. et al. Equality of educational opportunity. Washington: National Center for Educational Statistics, 1966.

COSTA, J. A. et al. O fenômeno das explicações: Aspectos da realidade portuguesa e do contexto global. Ensaio: Avaliação e políticas públicas em educação. Rio de Janeiro, v. 15, n. 57, p. 475-488, out.dez. 2007. https://doi.org/10.1590/S0104-40362007000400002

COSTA, J. A. et al. Reforço escolar: Análise comparada dos meandros de um fenômeno em crescimento. Educação Unisinos, São Leopoldo, v. 17, n. 3, p. 205-214, set.-dez. 2013. https://doi.org/10.4013/ edu.2013.173.04

FÁVERO, L. P.; BELFIORE, P. Manual de análise de dados. Rio de Janeiro: Elsevier, 2017.

GOMES, C. A. et al. Sistema educativo sombra: Recortes no Brasil e em Portugal. Revista Ibero-americana de Educação, v. 52, n. 6, p. 1-14, 2010. https://doi.org/10.35362/rie5261768

GOUVEIA, A.; NETO-MENDES, A. A. O mercado do reforço escolar: A procura e a oferta de cursinhos comerciais na cidade de Brasília. Revista Ciências Humanas UNITAU, Taubaté, v. 7, n. 2, p. 17-41, jul.-dez. 2014. https://doi.org/10.32813/2179-1120.2014.v7.n2.a149

GREENACRE, M. J. La práctica del análisis de correspondencias. Barcelona, Fundación BBVA, 2008.

HANUSHEK, E. A. Assessing the effects of school resources on student performance: An update. Educational Evaluation and Policy Analysis, v. 19, n. 2, p. 141-164, 1997.

HEY, A. P. Elites, no plural. Tempo Social, v. 29, n. 3, p. 1-8, 2017. https://doi.org/10.11606/0103-2070. ts.2017.126527

HUSSEIN, M. G. A. Private tutoring: A hidden educational problem. Educational Studies in Mathematics, v. 18, n. 1, p. 91-96, 1987. https://doi.org/10.1007/BF00367916

KIRBY, P. Shadow schooling: Private tuition and social mobility in the UK. The Sutton Trust, 2016.

LIU, J.; BRAY, M. Determinants of demand for private supplementary tutoring in China: Findings from a national survey. Education Economics, v. 25, n. 2, p. 205-2018, 2017. https://doi.org/10.1080/09645292.20 16.1182623

NETO, M. C. H. P. M. A procura de explicações: A razão dos pais. Dissertação (Mestrado Em Ciências da Educação). Departamento de Ciências da Educação, Universidade de Aveiro, Aveiro, 2006.

NOGUEIRA, M. A. Favorecimento econômico e excelência escolar: Um mito em questão. Revista Brasileira de Educação, n. 26, p. 133-144, maio-ago. 2004. https://doi.org/10.1590/S1413-24782004000200011 
SILOVA, I. Private tutoring in Eastern Europe and Central Asia: Policy choices and implications. Compare, v. 40, n. 3, p. 327-344, 2010. https://doi.org/10.1080/03057920903361926

SOUTHGATE, D. E. Determinants of shadow education: A cross-national analysis. Dissertation (Doctorate in Philosophy) - Graduate Programm in Sociology, Ohio State University, Ohio, 2009.

STEVENSON, D. L.; BAKER, D. P. Shadow education and allocation in formal schooling: Transition to university in Japan. American Journal of Sociology, v. 97, n. 6, p. 1639-1657, 1992.

\section{Sobre o Autor}

Fernando Vizotto Galvão é graduado em Economia pela Faculdade de Economia, Administração, Contabilidade e Atuária da Universidade de São Paulo (USP). Mestre e doutorando em Educação pela Faculdade de Educação da USP. Especialista em Políticas Públicas do governo do estado de São Paulo. Desenvolve pesquisas sobre desigualdades educacionais e economia da educação, com ênfase em análise de dados educacionais.

Recebido: 10 dez 2019

Aceito: 01 jun 2020 